\title{
DJ-1 mutations are a rare cause of recessively inherited early onset parkinsonism mediated by loss of protein function
}

\author{
P J Lockhart, S Lincoln, M Hulihan, J Kachergus, K Wilkes, G Bisceglio, D C Mash, M J Farrer
}

J Med Genet 2004;41:e22 (http://www.jmedgenet.com/cgi/content/full/41/3/e22). doi: 10.1136/jmg.2003.011106

$P$ arkinson's disease (PD; OMIM \#168600) is a common neurodegenerative disorder characterised by bradykinesia, resting tremor, muscle rigidity, and postural instability. The pathological features include loss of dopaminergic neurones, in particular within the substantia nigra pars compacta, and eosinophilic, cytoplasmic inclusions termed Lewy bodies. ${ }^{1}$ Although rare, familial forms of parkinsonism provide a powerful tool to determine the molecular pathways perturbed in idiopathic PD. ${ }^{23}$

Three loci have been associated with autosomal recessive early onset parkinsonism (EO-PD): parkin (PARK2), ${ }^{4}$ the as yet unidentified PARK6, ${ }^{5}$ and DJ-1 (PARK7). ${ }^{6}$ Loss of Parkin function is the predominant genetic cause of EO-PD in Japanese, Northern European, North American, and North African populations. Homozygous and compound heterozygous parkin mutations account for approximately $49 \%$ of familial and $19 \%$ of sporadic EO-PD (with onset prior to 45 years)..$^{7-13}$ Although the gene has yet to be identified, linkage analysis of chromosome lp36 interval suggests that PARK6 mutations may also account for numerous families with EO-PD across Europe. ${ }^{14}$ Most recently, mutations in $D J-1$ (PARK7) were identified in consanguineous Dutch and Italian kindreds affected with EO-PD. In the Dutch kindred, a $14 \mathrm{~kb}$ genomic deletion removed the promoter region and the first five exons $(\Delta \mathrm{l}-5)$. In the Italian kindred, a highly conserved amino acid (leucine) was altered to proline (497 bp T $\rightarrow$ C; L166P). This substitution was predicted to disrupt protein folding and was demonstrated to affect cellular localisation. ${ }^{6}$ Both mutations showed complete segregation with disease in homozygous individuals, while heterozygous carriers were unaffected, suggesting that loss of function of $D J-1$ is pathogenic. To date, $D J-1 \Delta \mathrm{l}-5$ and $497 \mathrm{bp}$ $\mathrm{T} \rightarrow \mathrm{C}$ (L166P) mutations have only been reported in the original Dutch and Italian families and in ethnically matched control individuals. ${ }^{6}$ There have been no reports on the frequency of $D J-l$ variants in EO-PD generally, or in samples from other populations.

DJ-1 appears to have several functions within the cell. Originally recognised as a c-myc interacting protein, ${ }^{15}$ DJ-1 has been identified as an infertility related protein, ${ }^{16}$ associated with RNA stabilisation ${ }^{17}$ and shown to convert to a more acidic form under conditions of oxidative stress. ${ }^{18}$ Currently, the mechanism by which loss of DJ-1 causes parkinsonism is unclear.

With this background, we performed a comprehensive mutation analysis of $D J-1$ in a cohort of 49 EO-PD probands, white subjects derived from North America and representing several European ethnicities. One sequence alteration was identified in one patient, a heterozygous $293 \mathrm{bp} \mathrm{G} \rightarrow \mathrm{A}$ transition, resulting in an $\mathrm{R} 98 \mathrm{Q}$ change to the protein sequence. Subsequently, the functional properties of DJ-1 wild type, Q98, and P166 proteins were assessed.

\section{Key points}

- Mutations in DJ-1/PARK7 were recently identified as a cause of early onset parkinsonism (EO-PD). To identify known and novel DJ-1 mutations and assess their frequency, we performed a comprehensive analysis of $D J-7$ in 49 EO-PD patients previously excluded for mutations in the parkin gene.

- There were no alterations to DJ-1 in 48 of the 49 cases studied. Mutations in DJ-1 appear to be a rare cause of recessively inherited EO-PD, accounting for $<1 \%$ of cases with onset prior to 50 years.

- A novel $G \rightarrow A$ transition resulted in a $R 98 Q$ heterozygous substitution in one affected individual; however, no other sequence alterations or exon deletion/ duplication(s) were detected. The transition was identified in six of 258 ethnically matched controls. This alteration probably represents a rare polymorphism.

- Functional analysis of the DJ-1 P166 variant demonstrated a reduced steady state protein level that could be rescued by proteasomal inhibition. Loss of DJ-1 protein is sufficient to explain disease pathogenesis for both $\Delta 1-5$ and P166 mutations when recessively inherited in EO-PD.

\section{MATERIALS AND METHODS \\ Patients}

All subjects were evaluated by a neurologist specialising in movement disorders and met the criteria for $\mathrm{PD} .{ }^{19}$ Age of onset of PD symptoms was prior to 50 years (mean (SD) 38.6 (8.1) years; male:female $=32: 9$, unknown gender $=8 ; n=49$ ), and two (possible PD, $\mathrm{n}=33$ ) or three (probable PD, $\mathrm{n}=15$ ) of the four cardinal signs of PD were noted. Patients displayed no atypical features or evidence of secondary parkinsonism caused by other neurological disease or drugs/toxins, except for one, where the patient was diagnosed with resting tremor/parkinsonism but was included in this study because of the very early age of onset ( 18 years). All patients were white, of diverse North American and/or Northern European ethnicity. Twenty four probands were defined as sporadic $\mathrm{PD}$, while 22 probands had a family history of PD, here defined as having one or more first degree relatives with $\mathrm{PD}$, and three probands

Abbreviations: EO-PD, early onset parkinsonism; ORF, open reading frame; PD, Parkinson's disease 
had an unknown family history. Three cases had a family history compatible with recessive inheritance, seven were suggestive of dominant transmission, and the remainder could not be assessed due to lack of pedigree information. All probands were screened for parkin mutations by gene dosage and direct sequencing as described previously ${ }^{11}$ and found to be negative.

\section{Genetic analysis}

Informed consent was obtained under an institutional review board approved protocol prior to the study. A $10-20 \mathrm{ml}$ venous blood sample was drawn, and immortalised lymphoblastoid cells were generated by Epstein-Barr virus transformation using standard procedures. Total RNA was isolated using Trizol reagent (Invitrogen, Carlsbad, CA, USA) according to the manufacturer's instructions. Northern blot was performed essentially as described previously. ${ }^{20}$ The probe corresponded to the 3'UTR region of the pcDNA3.1 vector and was specific for plasmid derived transcripts. Genomic DNA was extracted using standard techniques, and semi-quantitative multiplex PCR assays were developed to detect exon rearrangements (deletions and duplications). Hex tagged, fluorescently labelled forward primers for $D J-1$ exons (table 1) were optimised in pooled sets of three primer pairs for multiplexing with an internal control. An initial $95^{\circ} \mathrm{C}$ denaturation ( 5 minutes) was followed by 23 cycles of $95^{\circ} \mathrm{C}$ (30 seconds), $53^{\circ} \mathrm{C}$ (45 seconds), and $68^{\circ} \mathrm{C}$ (2.5 minutes), with a final extension $68^{\circ} \mathrm{C}(5$ minutes $)$. PCR products were purified and diluted to give peak heights in the $1000 \rightarrow 3000$ scalar range, ensuring accurate assessment of peak area on an ABI 3100 analyser using Genotyper ${ }^{\mathrm{TM}}$ software.

The entire DJ-1 ORF was amplified by RT-PCR using SuperScript II reverse transcriptase (Invitrogen) and a 60$50^{\circ} \mathrm{C}$ touchdown protocol over 35 cycles. The forward primer corresponded to base pairs 23-40 of the Genbank sequence AF021819 (5'-TGCGTTCACTTTCAGCCT-3') and the reverse primer to base pairs 764-783 (5'-TGTGACTTCCATACTT CCGC-3'). Products were analysed for size alterations by electrophoresis in $1.5 \%$ agarose gels and sequenced using the BigDye Terminator Reagent mix (version l.1) and an ABI3100 automated sequencer. Heterozygote base calls and sequence alignment were performed with Sequencher ${ }^{\mathrm{TM}}$ (Gene Codes Corp., Ann Arbor, MI, USA).

The $293 \mathrm{bp} \mathrm{G} \rightarrow \mathrm{A}$ transition disrupts an Mspl site. To assay for this alteration, a $294 \mathrm{bp}$ fragment was amplified from genomic DNA (forward primer, 5'-GTGAGTGATTGGTTAGT GGC-3' and reverse primer 5' - ATCTCTGAAATGACACCAAC TT-3'), using a $60-50^{\circ} \mathrm{C}$ touchdown protocol over 35 cycles. Digestion with Mspl resulted in two fragments of 194 and $100 \mathrm{bp}$ for the wild type sequence and three fragments (294, 194, and $100 \mathrm{bp}$ ) if the $293 \mathrm{bp} \mathrm{G} \rightarrow \mathrm{A}$ transition was present as a heterozygous alteration.

\section{DJ-1 constructs, cell culture, and Western blotting}

Full-length cDNA for $D J-1$ was amplified as above and cloned into the mammalian expression vector pcDNA3.1-V5HIS/ TOPO (Invitrogen). The resulting recombinant protein encoded an in frame V5 epitope at the $\mathrm{C}$ terminus. The R98Q and L166P constructs were generated with the Transformer $^{\mathrm{TM}}$ mutagenesis kit (BD Biosciences Clontech, Palo Alto, CA, USA). All constructs were fully sequenced to confirm that the appropriate alterations were generated. HEK293 cells were cultured in Optimem supplemented with $10 \%$ fetal bovine serum (Invitrogen). Lactacystin and MG132 (a specific inhibitor of the proteasome beta subunit and a reversible, transition state inhibitor of the proteasome respectively ${ }^{21}$ ), used at the concentrations indicated in the text, were purchased from Calbiochem (EMD Biosciences, San Diego, CA, USA). Transient transfections were performed
Table 1 Primer sets and pools used for DJ-1 gene dosage analysis

\begin{tabular}{|c|c|c|}
\hline Primer & Sequence & $\begin{array}{l}\text { Product } \\
\text { (bp) }\end{array}$ \\
\hline $\begin{array}{l}\text { DJ-1 El F } \\
\text { DJ-1 E1 R }\end{array}$ & $\begin{array}{l}\text { [Hex] 5'-GCTGTCCAGCTAGAAACTCC } \\
5^{\prime} \text { - GACACCGTCCAGCACCC }\end{array}$ & 302 \\
\hline DJ-1 E2 F & [Hex] 5'-CTCTGCTTGAAAATGCTCC & 392 \\
\hline DJ-1 E2 R & 5'-GGCAAGACATAACAAGCG & \\
\hline DJ-1 E3 F & [Hex] 5'-TTAAAGACAGTGTACTCTGAATT & 388 \\
\hline DJ-1 E3 R & $5^{\prime}$-CATCCAGCCACCCACTTAC & \\
\hline DJ-1 E4 F & [Hex] 5'-GGCTATCTCCTGTACTTCCC & 297 \\
\hline DJ-1 E4 R & 5'-TCACAGCCTCCTCCCGAA & \\
\hline DJ-1 E5 F & [Hex] 5'- GTGAGTGATTGGTTAGTGGC & 293 \\
\hline DJ-1 E5 R & 5'-ATCTCTGAAATGACACCAACTT & \\
\hline DJ-1 E6 F & [Hex] 5'-CTCAAGCAATTाTCTACCT & 367 \\
\hline DJ-1 E6 R & 5'-GAGGCTGAGAGAGAAGAATCG & \\
\hline DJ-1 E7 F & [Hex] 5'-CGT CTITCTCGTCACATAGC & 360 \\
\hline DJ-1 E7 R & 5'-TGTGACTTCCATACTTCCGC & \\
\hline Control F & [Hex] 5'-ACGTTCCTGATAATGGGATC & 328 \\
\hline Control R & 5'-CCTCTCTCTACCAAGTGAGG & \\
\hline
\end{tabular}

Primers were pooled in sets of two $D J-1$ exons and the control. The sets and primer concentrations were as follows. Set 1: exon $4(0.6 \mu \mathrm{mol} / \mathrm{l})$, exon $2(0.8 \mu \mathrm{mol} / \mathrm{l})$, and control $(8 \mu \mathrm{mol} / \mathrm{l})$; set 2: exon $1(0.8 \mu \mathrm{mol} / \mathrm{l})$, exon $6(0.6 \mathrm{umol} / \mathrm{l})$, and control $(0.8 \mathrm{\mu mol} / \mathrm{l})$; set 3 ; exon $5(0.8 \mathrm{\mu mol} /$

I), exon $7(0.8 \mu \mathrm{mol} / \mathrm{l})$, and control $(0.8 \mu \mathrm{mol} / \mathrm{l})$; and set 4 : exon 3 $(1.2 \mu \mathrm{mol} / \mathrm{l})$ and control $(0.6 \mu \mathrm{mol} / \mathrm{l})$.

with FuGENE6 reagent (Roche Molecular Biology, Indianapolis, IN, USA) according to the manufacturer's protocols. Western blotting was performed essentially as described previously. ${ }^{22}$ Primary antibodies were monoclonal anti-V5 (Invitrogen), monoclonal anti-GFP (Chemicon International, CA, USA), and monoclonal anti- $\beta$-actin (Sigma, St Louis, MO, USA). Antibody binding was revealed using peroxidase conjugated secondary antibodies (Jackson ImmunoResearch Labs, West Grove, PA, USA) and enhanced chemiluminescence (Amersham Biosciences, Piscataway, NJ, USA) according to the manufacturers' protocols. Quantitation was performed using an Alpha Innotech gel documentation system (Alpha Innotech Corp, San Leandro, CA, USA).

\section{RESULTS}

\section{Mutation screening}

A comprehensive gene dosage analysis of all 7 DJ- 1 exons did not detect any alteration in exon copy number, indicative of duplication and/or deletion, in any patient sample. All samples were analysed independently at least twice. For exons $1^{\mathrm{A} / \mathrm{B}}$ through to 5, haploid genomic controls were processed in parallel to confirm sensitivity and accurate quantitation of exon dosage. For all exons where a haploid control sample was available, we could accurately detect $\sim 50 \%$ reduction in peak area, indicative of exon deletion (fig 1A).

For all patient samples, PCR amplification of the DJ-I cDNA resulted in two products of 819 and 761 bp respectively. The different product sizes arise via alternate splicing of the non-coding exon $\mathrm{l}^{\mathrm{B}}$, as reported previously. ${ }^{6}$ No PCR products of a different size were observed for any subject, suggesting there were no mutations affecting consensus splice motifs. Similarly, no sequence alterations were detected in the untranslated or coding portion of the DJ-I cDNA in 48 of the patients examined. Taken with the gene dosage results, this study suggests that alterations in $D J-1$ are a rare cause of EO-PD in the white population.

A single alteration in the open reading frame (ORF) of one proband was detected, a heterozygous $293 \mathrm{bp} \mathrm{G} \rightarrow$ A transition (numbering based on position 1 being $\mathrm{A}$ of the initiating start codon), resulting in a R98Q substitution in the protein sequence. Semi-quantitative analysis of cDNA demonstrated 


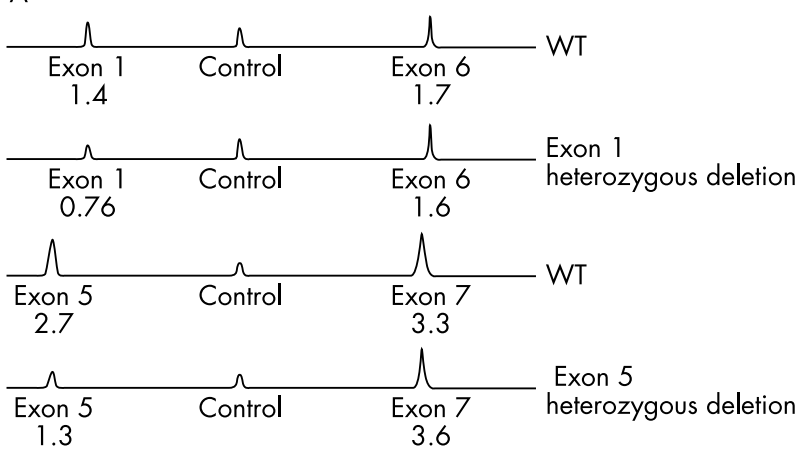

B

Human $\quad \begin{aligned} & \star \star \star \star \star \\ & \text { LSESAAVKE }\end{aligned}$

Monkey LSESAAVKEILKEQENRKGLIAAICAGPTAL

Chicken LSESAAVKDILKDQESRKGLIAAICAGPTAL

Mouse LSESPMVKEILKEQESRKGLIAAICAGPTAL

At. Salmon LSESPAVKEVLKDQEGRKGLIAAICAGPTAL

Xenopus LSESPVVKEVLKEQEAKKGLIAAICAGPTAL

Drosophila ---SSAVGDVLRCQESKGGLIAAICAAPTAL

Figure 1 Genetic analysis of $D J-1$ in EO-PD patients. (A) A representative exon dosage chromatogram demonstrating detection of heterozygous exon 1 and exon 5 deletions. Ratios are generated by dividing the area under the $D J-1$ exon peak by the area under the control peak. A ratio half of that observed for wild type is indicative of a heterozygous exon deletion. (B) ClustalW alignment of DJ-1 proteins. The R98 amino acid is indicated in bold. Accession numbers are those referenced in Bonifati et al. ${ }^{\circ}$

that each allele was equally expressed. To comprehensively search for a second $D J-1$ sequence alteration in this patient, we amplified and sequenced each exon from genomic DNA (for primer sequences, see table 1). No other sequence alterations were detected in the coding sequence or in a minimum of $50 \mathrm{bp}$ flanking each intron. The $293 \mathrm{bp} \mathrm{G} \rightarrow \mathrm{A}$ transition was subsequently identified in 6 of 258 ethnically matched controls as a heterozygous alteration.

\section{Analysis of DJ-1 protein variants}

The R98 amino acid is well conserved in evolution (fig 1B) and the R98Q substitution may have significant effects on protein structure and localisation, as reported for the L166P alteration. To test this possibility, we generated non-tagged and V5 tagged constructs encoding the wild type, P166, and Q98 forms of DJ-1 and transfected HEK293 cells. The cells were harvested, split into two pellets and analysed by Northern and Western blotting. The Northern blot demonstrated that significant levels of $D J-1$ mRNA generated by the plasmid was being produced for each DJ-1 construct (fig 2), suggesting that efficient transfection had occurred. However, the steady state levels of the P166 protein were significantly lower than the wild type or Q98 forms (fig 3), and required extended exposure times or increased protein loading to be visualised. Similar results were obtained when transfected cells were examined by indirect immunfluorescence for plasmid derived DJ-1 protein. Wild type and Q98 DJ-1 demonstrated robust levels of expression and displayed diffuse cytoplasmic and nuclear immunoreactivity, whereas P166 DJ-1 levels were significantly reduced (data not shown).

Two major mechanisms of intracellular protein degradation are the lysosomal pathway and the ubiquitin proteasome system. Inhibition of the lysosome with $100 \mu \mathrm{mol} / \mathrm{l}$ chloroquine or $20 \mathrm{~m} \mathrm{~mol} / \mathrm{l}$ ammonium chloride ${ }^{23}$ did not alter steady state levels of V5-wildtype, V5-Q98, or V5-P166 DJ-1 (data not shown). Similarly, treatment of V5-wildtype and

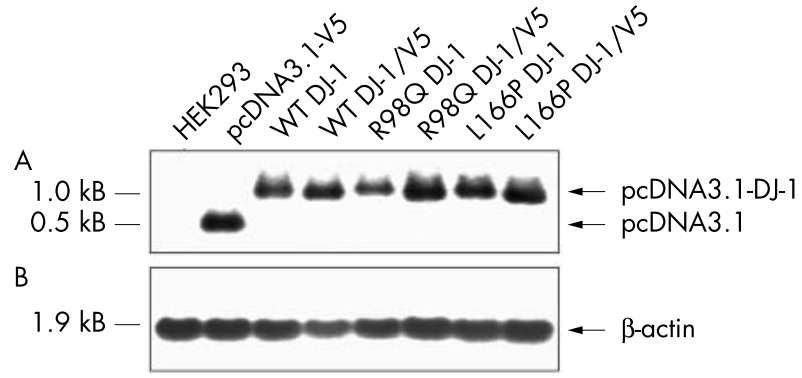

Figure 2 Northern blot analysis of HEK293 cells transfected with pcDNA3.1-DJ-1. HEK293 cells were transiently transfected with the indicated constructs and total RNA was isolated and analysed by Northern blotting. (A) The blot was probed with the $3^{\prime}$ UTR sequence of the transgene. Strong expression of non-tagged and V 5 tagged wild type DJ-1 (lanes 3 and 4), non-tagged and V5 tagged R98Q DJ-1 (lanes 5 and 6), and non-tagged and V5 tagged L166P DJ-1 (lanes 7 and 8) was observed. (B) The same blot was subsequently reprobed with the $\beta$ actin CDNA probe to demonstrate loading and integrity of the RNA. Approximate sizes in kilobase pairs are indicated.

V5-Q98 DJ-1 transfected cells for 14 hours with $5 \mu \mathrm{mol} / \mathrm{l}$ and $10 \mu \mathrm{mol} / \mathrm{l}$ lactacystin, a specific proteasomal inhibitor, did not significantly alter the levels of these two forms of recombinant DJ-1 protein. However, this treatment did result in significantly elevated levels of V5-P166 recombinant protein (representative results shown in fig 4). To confirm that these observations were the result of proteasome inhibition, we repeated the experiment using a second inhibitor (MG-132) and GFP $\mu$, an in vivo indicator of proteasomal inhibition. ${ }^{24}$ HEK293 cells were transiently transfected with the GFP $\mu$ reporter and V5-P166 DJ-1 constructs. Treatment with increasing concentrations of MG-132 resulted in a significant, dose dependent increase in the steady state levels of GFP $\mu$, confirming effective proteasome inhibition. Similarly, steady state levels of V5P166 recombinant protein were significantly elevated (fig 5A). Quantitation of three independent experiments performed in triplicate demonstrated that steady state V5-P166 DJ-1 increased greater than two-fold following exposure to $5 \mu \mathrm{mol} / \mathrm{l} \mathrm{MG}-132$ for 14 hours (fig 5B). This corresponded to approximately $20 \%$ of the steady state level of the wild type and Q98 forms of DJ-1. The lower molecular weight bands consistently observed in the MG-132 treated V5-P166 DJ-1

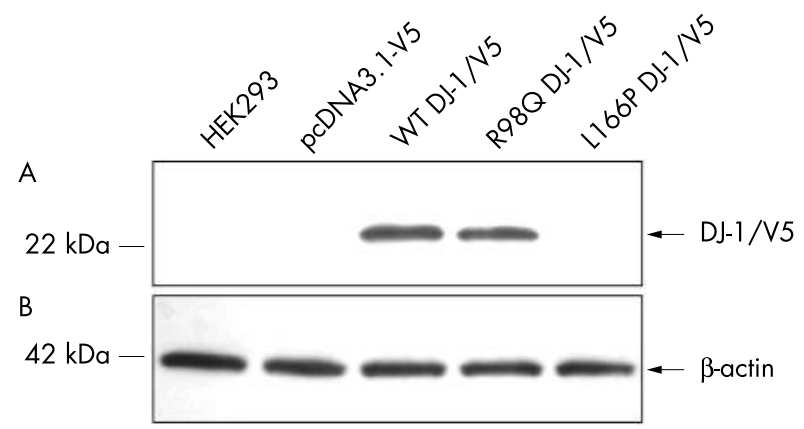

Figure 3 Western blot analysis of HEK293 cells transfected with pcDNA3.1-DJ-1. HEK293 cells were transiently transfected with no vector (lane 1), empty vector (lane 2), V5 tagged wild type DJ-1 (lane 3), V5 tagged R98Q DJ-1 (lane 4), and V5 tagged L166P DJ-1 (lane 5). Total protein was isolated and analysed by SDS-PAGE and Western blotting. (A) The blot probed with the V5 antibody to identify recombinant V5 tagged DJ-1. (B) The same blot reprobed with the $\beta$ actin antibody to confirm equivalent protein loading $(20 \mu \mathrm{g}$ protein per lane). Approximate sizes in kDa are indicated (MultiMark Standard, Invitrogen). 


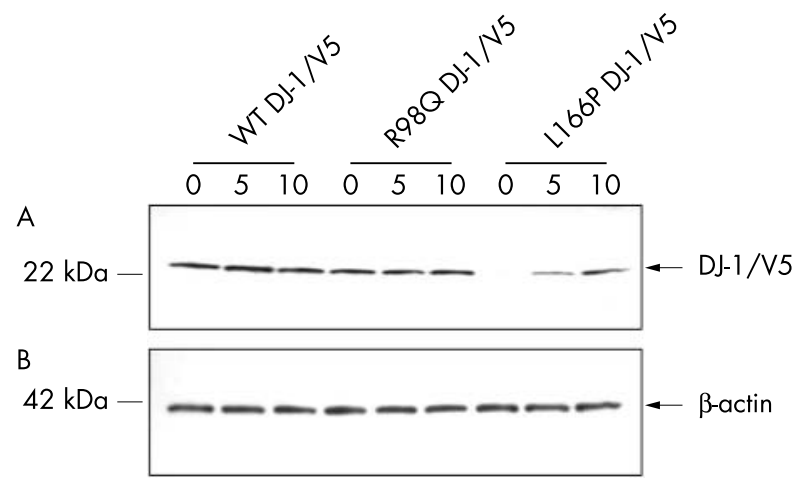

Figure 4 Effects of lactacystin treatment on wild type, Q98, and P166 DJ-1. HEK293 cells were transiently transfected with V5 tagged wild type DJ-1 (lanes 1-3), V5 tagged R98Q DJ-1 (lanes 4-6), and V5 tagged L166P DJ-1 (lanes 7-9), and treated with 0,5 , or $10 \mu \mathrm{mol} / /$ lactacystin for 14 hours. Total protein was isolated and analysed by SDS-PAGE and Western blotting. (A) The blot was probed the V5 antibody to identify recombinant $\mathrm{V} 5$ tagged DJ-1. (B) The same blot was reprobed with the $\beta$-actin antibody to confirm equivalent protein loading $(20 \mu \mathrm{g}$ protein per lane). Approximate sizes in kDa are indicated (MultiMark Standard, Invitrogen).

cells probably represent breakdown products of the full length protein.

\section{DISCUSSION}

Genetic approaches are rapidly refining the causes of early onset $\mathrm{PD}$, a complex disorder with a multifactorial genetic aetiology. ${ }^{25}$ However, the frequency of DJ-1 (PARK7) mutations in parkinsonism has yet to be fully evaluated. Apart from the initial description of mutations in $D J-1$ causing EO$\mathrm{PD}$, there have been no further reports examining different EO-PD cases or populations. Although pathogenic mutations were reported in two consanguineous European kindreds, analysis of nine additional EO-PD families and 22 sporadic EO-PD cases failed to identify additional $D J-1$ mutations. ${ }^{6}$ These observations suggest that mutations in $D J-1$ are not a common cause of EO-PD, analogous to the low frequency of autosomal dominant PD resulting from mutations in $\alpha$ synuclein. However, in the prior report, EO-PD cases were not excluded for parkin mutations, nor was $D J-1$ gene dosage analysis performed. Interestingly, $D J-1$ maps to a fragile region of $1 \mathrm{p} 36$ analogous to the FRA6E/parkin locus, suggesting that $D J-1$ may also be prone to deletion and loss of heterozygosity. ${ }^{26}{ }^{27}$ In this study, we assessed all possible variants within the DJ-l gene in a cohort of EO-PD cases, formerly excluded from having mutations within the parkin (PARK2) gene. Our methods included RT-PCR, direct sequencing of cDNA, and exon dosage methods. We did not detect any alterations in exon copy number, PCR product size, or cDNA sequence in 48 of the 49 patients examined. A single heterozygous alteration in the ORF of one proband was detected, which resulted in a R98Q substitution in the protein sequence. However, a second sequence alteration in the alternate allele was not identified, and the alteration was also detected in control samples, suggesting that it represents a rare polymorphism. Our results suggest that $D J-1$ mutations are rare in EO-PD, as we also failed to identify any mutations in a cohort of $4 \mathrm{l}$ EO-PD cases of ethnic Chinese descent originating from Taiwan (manuscript in preparation). Additionally, $D J-1$ sequence alterations were detected in only one of 107 EO-PD patients in a separate study (Dr S Hague, personal communication).

Recessive inheritance of DJ-1 mutations appears to be a prerequisite for EO-PD, as at least five carriers of the DJ-1 $\Delta \mathrm{l}-5$ mutation and three carriers of the P166 substitution
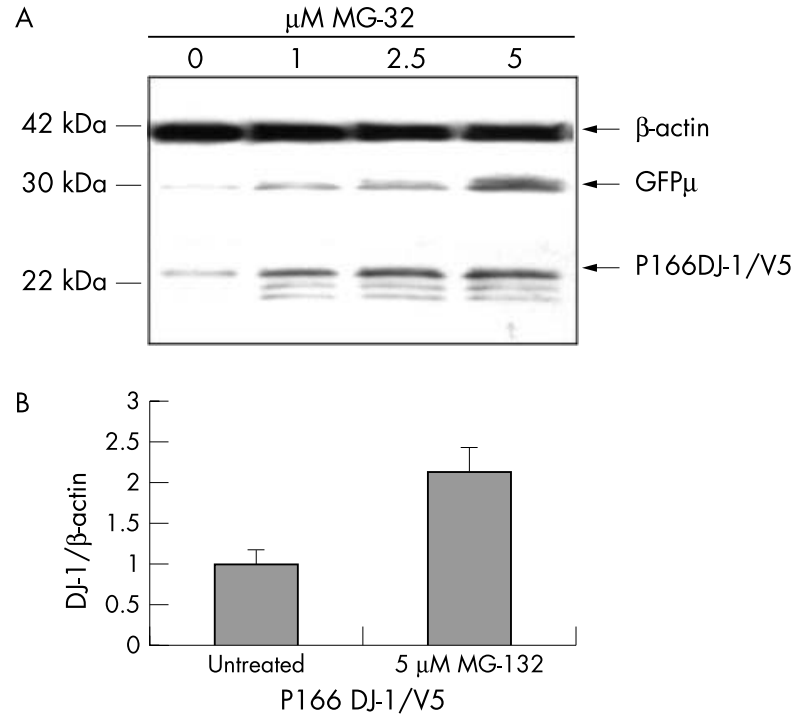

Figure 5 Stabilising effects of proteasomal inhibition on L166P DJ-1. (A) HEK293 cells were transiently transfected with the GFP reporter construct and V5 tagged L166P DJ-1. Cells were treated with 0, 1, 2.5, or $5 \mu \mathrm{mol} / \mathrm{l}$ MG-132 for 14 hours. Total protein was isolated and analysed by SDS-PAGE and Western blotting. The blot was probed with the V5 antibody to identify recombinant V5 tagged DJ-1. The same blot was reprobed with the $\beta$-actin antibody to confirm equivalent protein loading and the GFP antibody to demonstrate proteasomal inhibition. Approximate sizes in kDa are indicated (MultiMark Standard, Invitrogen). (B) Quantification of three independent experiments performed as above. Transfected cells were treated with 0 or $5 \mu \mathrm{mol} / \mathrm{I}$ MG-132 for 14 hours and analysed for recombinant DJ-1 and $\beta$-actin by Western blotting. The DJ-1/ $\beta$-actin ratio of the untreated cells was assigned a value of 1 and the treated samples were normalised. Each experiment was performed in triplicate, results represent the mean (SD).

remain unaffected. ${ }^{28}{ }^{29}$ However, as the disease phenotype in the Q98 carrier was of very early onset, we explored the functional properties of the variant protein.

Northern and Western blot analysis of wild type and Q98 DJ-1 transfected cells demonstrated robust levels of expression. In contrast, Northern blot analysis showed that significant levels of plasmid generated P166 DJ- 1 transcript was being produced but that the P166 DJ-1 protein was practically undetectable. We hypothesised that the P166 alteration might destabilise the protein, increasing turnover of the mutant compared to wild type DJ-1. To further investigate the mechanism, we treated cells expressing wild type and variant DJ-1 with proteasomal inhibitors (lactacystin and MG-132) at concentrations previously shown to inhibit proteasomal function but not induce significant cellular toxicity. ${ }^{30}$ Treatment with proteasome inhibitors did not significantly affect the steady state level of wild type or Q98 DJ-1, but did significantly increase the steady state levels of both P166 DJ-1 and the in vivo GFP reporter protein. Our results suggest P166 DJ-1 is rapidly and efficiently degraded by the proteasome. The molecular basis for enhanced degradation of P166 DJ-1 by the proteasome is unknown. The 166 position of DJ-1 is predicted to form a conserved helix, ${ }^{6}$ and proline can disrupt helix formation. ${ }^{31}$ Recent crystallisation data support this hypothesis, demonstrating that the 166 position is important for helix formation and the generation of a hydrophobic core between three helices. The P166 alteration appears to prevent DJ-1 dimerisation and crystallisation. ${ }^{32}$ This may alter protein conformation allowing/enhancing ubiquitylation by a currently unknown E3 protein-ubiquitin ligase. While lysine 130 is proposed as a site for sumoylation, ${ }^{33}$ DJ-1 encodes several lysine residues that are potential targets for ubiquitylation. Interestingly, a 
proline residue can function directly as a targeting determinate for E3 protein-ubiquitin ligases. ${ }^{34}$ Additionally, not all proteins that are degraded by the proteasome are ubiquitylated..$^{35}$ Future studies will be required to distinguish between these possibilities.

In conclusion, loss of DJ-1 protein is sufficient to explain disease pathogenesis for both $\Delta \mathrm{l}-5$ and Pl66 mutations, when recessively inherited in EO-PD. Although mitochondrial relocalisation of DJ-1 P166 has been noted in COS7 cells, ${ }^{6}$ our work suggests it is a minor observation in HEK293 cells compared with the dramatic decrease in steady state protein levels. These differences may be the result of alternate cell models or be an artefact of cell culture conditions. Examination of the amount and localisation of DJ-1 in patient samples derived from the Italian kindred could help to resolve these observations. Although further case-control studies of the $293 \mathrm{bp} \mathrm{G} \rightarrow \mathrm{A}$ transition identified here need to be performed, our results suggest the R98Q substitution represents a rare polymorphic change, not a pathogenic mutation. DJ-1 mutations are rare; there are few polymorphic or pathogenic coding variants in the gene in white populations. Hence, PARK7 is unlikely to explain EO-PD within individuals in which mutations in PARK2 have been excluded. Nevertheless, identifying the molecular components of parkinsonism in rare families is useful, as these proteins may be part of a molecular pathway perturbed in idiopathic PD. Furthermore, genetic insights allow the creation of cellular and animal models and will ultimately provide a rational basis for novel drug design.

\section{ACKNOWLEDGEMENTS}

The authors express appreciation for the advice and support given by our laboratory colleagues and particularly thank all patients involved. We would like to thank Dr V Bonifati for control DNA from individuals with heterozygous $D J-1$ exonic deletions, Dr L Petrucelli and K Kehoe for the L166P DJ-1 construct, Dr D Dickson for helpful discussion and M Schreiber for technical assistance. We would also like to thank many clinicians particularly Drs J Aasly, K GwinnHardy, D B Calne, A Levey, R Wu, A Krygowska, P Chana, E Ashklog, Y Tsuboi, R Uitti and Z Wszolek, who were involved in clinical research on these patients. Samples were also made available through the NPF Brain Endowment Bank, University of Miami. This work was supported in part by an M H Udall NIH Parkinson's disease Center of Excellence grant. P J Lockhart is an Australian NHMRC CJ Martin Fellow and recipient of a Robert and Clarice Smith Fellowship in Neurodegenerative Diseases and Stroke.

\section{Authors' affiliations \\ P J Lockhart, S Lincoln, M Hulihan, J Kachergus, K Wilkes, G Bisceglio, M J Farrer, Department of Neuroscience, Mayo Clinic, Jacksonville, FL, USA \\ D C Mash, Department of Pathology, University of Miami, Miami, FL, USA}

Correspondence to: $\operatorname{Dr} \mathrm{P} J$ Lockhart, Birdsall Building, Mayo Clinic Jacksonville, 4500 San Pablo Road, Jacksonville, FL, USA, 32224; caseyandpaul@hotmail.com

Received 15 July 2003

Accepted 15 July 2003

\section{REFERENCES}

Fearnley JM, Lees AJ. Ageing and Parkinson's disease: substantia nigra regional selectivity. Brain 1991:114:2283-301.

2 Cookson MR. Pathways to parkinsonism. Neuron 2003;37:7-10.

3 Skipper L, Farrer M. Parkinson's genetics: molecular insights for the new millennium. Neurotoxicology 2002;23:503-14.

4 Kitada T, Asakawa S, Hattori N, Matsumine H, Yamamura Y, Minoshima S, Yokochi M, Mizuno Y, Shimizu N. Mutations in the parkin gene cause autosomal recessive juvenile parkinsonism. Nature 1998;392:605-8

5 Valente EM, Bentivoglio AR, Dixon PH, Ferraris A, lalongo T, Frontali M, Albanese A, Wood NW. Localization of a novel locus for autosomal recessive early-onset parkinsonism, PARK6, on human chromosome 1p35-p36. Am J Hum Genet 2001;68:895-900.
6 Bonifati V, Rizzu P, van Baren MJ, Schaap O, Breedveld GJ, Krieger E, Dekker MC, Squitieri $F$, lbanez $P$, Joosse $M$, van Dongen JW, Vanacore $N$ van Swieten JC, Brice A, Meco G, van Duijn CM, Oostra BA, Heutink P. Mutations in the DJ-1 gene associated with autosomal recessive early-onset parkinsonism. Science 2003:299:256-9.

7 Lucking CB, Durr A, Bonifati V, Vaughan J, De Michele G, Gasser T, Harhangi BS, Meco G, Denefle P, Wood NW, Agid Y, Brice A. Association between early-onset Parkinson's disease and mutations in the parkin gene. French Parkinson's Disease Genetics Study Group. N Engl J Med 2000;342:1560-7.

8 Abbas N, Lucking CB, Ricard S, Durr A, Bonifati V, De Michele G, Bouley S, Vaughan JR, Gasser T, Marconi R, Broussolle E, Brefel-Courbon C, Harhangi BS, Oostra BA, Fabrizio E, Bohme GA, Pradier L, Wood NW, Filla A, Meco G, Denefle P, Agid Y, Brice A. A wide variety of mutations in the parkin gene are responsible for autosomal recessive parkinsonism in Europe. French Parkinson's Disease Genetics Study Group and the European Consortium on Genetic Susceptibility in Parkinson's Disease. Hum Mol Genet 1999:8:567-74.

9 Kann M, Jacobs H, Mohrmann K, Schumacher K, Hedrich K, Garrels J, Wiegers K, Schwinger E, Pramstaller PP, Breakefield XO, Ozelius L, Vieregge $\mathrm{P}$, Klein $\mathrm{C}$. Role of parkin mutations in 111 community-based patients with early-onset parkinsonism. Ann Neurol 2002;51:621-5.

10 Periquet $M$, Lucking $C$, Vaughan J, Bonifati V, Durr A, De Michele G, Horstink $M$, Farrer $M$, Illarioshkin SN, Pollak P, Borg M, Brefel-Courbon C, Denefle P, Meco G, Gasser T, Breteler MM, Wood N, Agid Y, Brice A, French Parkinson's Disease Genetics Study Group, European Consortium on Genetic Susceptibility in Parkinson's Disease. Origin of the mutations in the parkin gene in Europe: exon rearrangements are independent recurrent events, whereas point mutations may result from founder effects. Am J Hum Genet 2001;68:617-26.

11 West A, Periquet $M$, Lincoln S, Lucking CB, Nicholl D, Bonifati V, Rawal N, Gasser T, Lohmann E, Deleuze JF, Maraganore D, Levey A, Wood N, Durr A, Hardy J, Brice A, Farrer M, French Parkinson's Disease Genetics Study Group, European Consortium on Genetic Susceptibility on Parkinson's Disease. The complex relationship between parkin mutations and Parkinson's disease. Am J Med Genet 2002;1 14:584-591.

12 Hedrich K, Marder K, Harris J, Kann M, Lynch T, Meija-Santana H, Pramstaller PP, Schwinger E, Bressman SB, Fahn S, Klein C. Evaluation of 50 probands with early-onset Parkinson's disease for Parkin mutations. Neurology 2002;58:1239-46.

13 Nichols WC, Pankratz N, Uniacke SK, Pauciulo MW, Halter C, Rudolph A Conneally PM, Foroud T. Linkage stratification and mutation analysis at the Parkin locus identifies mutation positive Parkinson's disease families. J Med Genet 2002:39:489-92.

14 Valente EM, Brancati F, Ferraris A, Graham EA, Davis MB, Breteler MM, Gasser T, Bonifati V, Bentivoglio AR, De Michele G, Durr A, Cortelli P, Wassilowsky D, Harhangi BS, Rawal N, Caputo V, Filla A, Meco G, Oostra BA, Brice A, Albanese A, Dallapiccola B, Wood NW, European Consortium on Genetic Susceptibility in Parkinson's Disease. PARK6-linked parkinsonism occurs in several European families. Ann Neurol 2002;51:14-8.

15 Nagakubo D, Taira T, Kitaura H, Ikeda M, Tamai K, Iguchi-Ariga SM Ariga $\mathrm{H}$. DJ-1, a novel oncogene which transforms mouse NIH3T3 cells in cooperation with ras. Biochem Biophys Res Commun 1997;231:509-13.

16 Wagenfeld A, Gromoll J, Cooper TG. Molecular cloning and expression of rat contraception associated protein 1 (CAP1), a protein putatively involved in fertilization. Biochem Biophys Res Commun 1998;251:545-9.

17 Hod Y, Pentyala SN, Whyard TC, El-Maghrabi MR. Identification and characterization of a novel protein that regulates RNA-protein interaction. J Cell Biochem 1999:72:435-44.

18 Mitsumoto A, Nakagawa Y, Takeuchi A, Okawa K, Iwamatsu A, Takanezawa Y. Oxidized forms of peroxiredoxins and DJ-1 on two dimensional gels increased in response to sublethal levels of paraquat. Free Radic Res 2001;35:301-10.

19 Gelb DJ, Oliver E, Gilman S. Diagnostic criteria for Parkinson disease. Arch Neurol 1999;56:33-9.

20 Lockhart PJ, Mercer JF. Cloning and expression analysis of the sheep ceruloplasmin cDNA. Gene 1999;236:251-7.

21 Lee DH, Goldberg AL. Proteasome inhibitors: valuable new tools for cell biologists. Trends Cell Biol 1998;8:397-403.

22 West A, Lockhart $P, O^{\prime}$ Farrell C, Farrer MJ. Identification of a novel gene linked to parkin via a bi-directional promoter. J Mol Biol 2003;326:11-19.

23 Musial A, Eissa NT. Inducible nitric-oxide synthase is regulated by the proteasome degradation pathway. J Biol Chem 2001 ;276:24268-73.

24 Bence NF, Sampat RM, Kopito RR. Impairment of the ubiquitin-proteasome system by protein aggregation. Science 2001;292:1552-5.

25 Gwinn-Hardy K, Farrer M. Parkinson's genetics: an embarrassment of riches. Ann Neurol 2002:51:7-8.

26 Smith DI, Huang H, Wang L. Common fragile sites and cancer. Int J Oncol 1998:12:187-96.

27 Smedley D, Sidhar S, Birdsall S, Bennett D, Herlyn M, Cooper C, Shipley J. Characterization of chromosome 1 abnormalities in malignant melanomas. Genes Chromosomes Cancer 2000;28:121-5.

28 Bonifati V, Breedveld GJ, Squitieri F, Vanacore N, Brustenghi P, Harhangi BS Montagna P, Cannella M, Fabbrini G, Rizzu P, van Duiin CM, Oostra BA, Meco G, Heutink P. Localization of autosomal recessive early-onset parkinsonism to chromosome 1p36 (PARK7) in an independent dataset. Ann Neurol 2002;51:253-6.

29 van Duijn CM, Dekker MC, Bonifati V, Galiaard RJ, Houwing-Duistermaat J J Snijders PJ, Testers L, Breedveld GJ, Horstink M, Sandkuijl LA, van Swieten JC, 
Oostra BA, Heutink P. Park7, a novel locus for autosomal recessive early-onset parkinsonism, on chromosome 1p36. Am J Hum Genet 2001;69:629-34.

30 Petrucelli L, O'Farrell C, Lockhart PJ, Baptista M, Kehoe K, Vink L, Choi P, Wolozin B, Farrer M, Hardy J, Cookson MR. Parkin protects against the toxicity associated with mutant alpha-synuclein: proteasome dysfunction selectively affects catecholaminergic neurons. Neuron 2002;36:1007-19.

31 Kim MK, Kang YK. Positional preference of proline in alpha-helices. Protein Sci 1999;8:1492-9.

32 Tao X, Tong L. Crystal structure of human DJ-1, a protein associated with early-onset Parkinson's diseasec. J Biol Chem 2003;278:31372-9.
33 Takahashi K, Taira T, Niki T, Seino C, Iguchi-Ariga SM, Ariga H. DJ-1 positively regulates the androgen receptor by impairing the binding of PIASx alpha to the receptor. J Biol Chem 2001;276:37556-63.

34 Jaakkola P, Mole DR, Tian YM, Wilson MI, Gielbert J, Gaskell SJ, Kriegsheim Av, Hebestreit HF, Mukherii M, Schofield CJ, Maxwell PH, Pugh CW, Ratcliffe PJ. Targeting of HIF-alpha to the von Hippel-Lindau ubiquitylation complex by $\mathrm{O}_{2}$-regulated prolyl hydroxylation. Science 2001;292:468-72

35 Verma R, Deshaies RJ. A proteasome howdunit: the case of the missing signal. Cell 2000;101:341-4. 